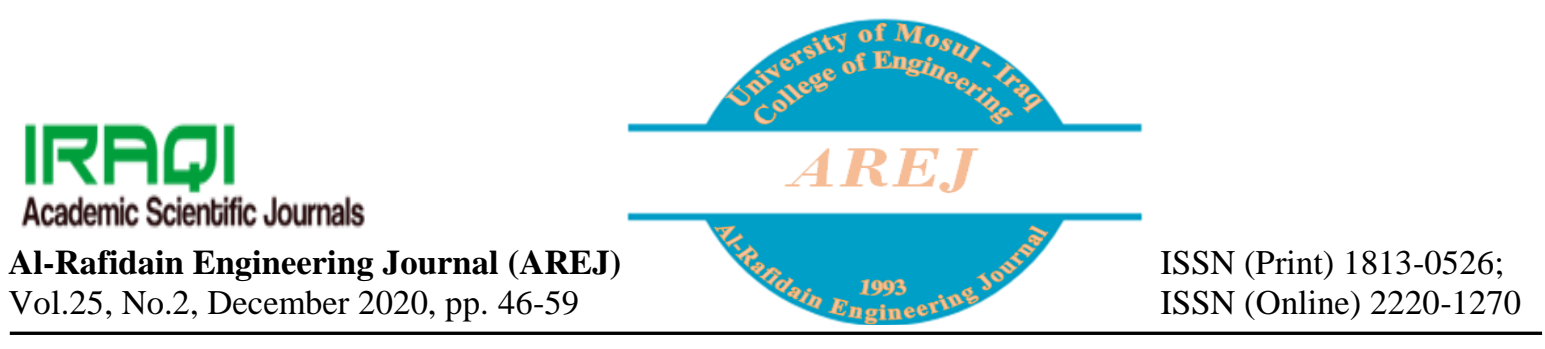

\title{
A Review of Solar Air Heaters: Techniques for Thermal Performance Enhancement
}

\author{
Omar Mohammed Hamdoon \\ eng.omar.m.hamdoon@uomosul.edu.iq \\ Mechatronics Engineering Department, Collage of Engineering, University of Mosul
}

Received: $15 / 9 / 2020$

Accepted: 6/10/2020

\begin{abstract}
The solar air heater is a simple device which captures solar energy. Producing hot air by using a solar air heater is a renewable energy heating technology used to process heat generation for space heating. Such systems produce heat at a minimum initial and running cost. Minimum maintenance like cleaning of collectors only is required. Many studies have studied the possibility of improving the performance of solar collectors and raising their thermal efficiency through additions and improvements that were added to the solar heater. Among these improvements are: Adding the extended surfaces to the upper or lower channels, or both, attaching baffles to the absorber plate surface, using corrugated absorber plate, and storing the extra thermal energy and releasing it during sunset. The objective of the present paper is to review the various studies dealing with previous improvements, to present the design modifications, in addition to summarizing their most important results. Based on the review, it is found that: Adding the fins and baffles together to the absorber plate surface of the single or double pass solar air heater has a great effect on improving the thermal efficiency. The use of a corrugated absorber plate leads to a significant increase in the efficiency of the solar air heater. The heat stored in the solar air heater can be used to produce useful heat for several hours after the absence of solar radiation and raise daily efficiency.
\end{abstract}

Keywords:

Solar air heater, performance enhancement, fins, baffles, corrugated absorber, PCM.

https://rengj.mosuljournals.com

Email: alrafidain_engjournall@uomosul.edu.iq

\section{INTRODUCTION}

The Solar Air Heater (SAH) is a simple device in which solar energy is converted into thermal energy to heat the air. The main components of the solar air heater are one or more glass cover, absorber plate, one or more airflow channels, insulation to reduce heat loss from both the bottom and sidewalls of the solar collector. These systems produce heat at minimal initial and running costs. It also requires minimal maintenance such as cleaning the transparent cover only. SAH is widely used to provide energy especially for applications that require low to medium heating temperatures. It is also used effectively for some applications including building heating, solar water desalination and crop drying [1-3]. SAH has many advantages compared to solar water heaters due to the absence of freezing or stagnation problems, and leaks. Moreover, it has a lower cost. SAHs are categorized according to the number of collector transparent cover, the absorber plate material, the absorber surface shape, the airflow pattern. Tyagia et al. [4] classified the SAHs according to the presence of energy storage or the presence of extended surfaces as well as the number of covers as shown in Figure (1). On the other hand, SAHs can be classified according to the number of air passages in a single or double pass, as well as according to the presence or absence of heat storage [5-6]. Figure (2) shows a single-pass solar air heater, in which air can flow in one way, either over the absorber plate or under it from the air inlet to the outlet. While Figure (3) shows a double-pass solar air heater. Airflow in double pass solar air heater may be either parallel or 
counter. Despite the wide applications of solar air heaters, the main challenge in this device is the low heat transfer rate and low efficiency due to various losses. Therefore, many previous studies have studied the possibility of improving the performance of solar collectors and raising their thermal efficiency through additions and improvements that have been added to the solar heater. Among these improvements are: adding extended surfaces to the upper or lower channels, or both, attaching baffles to the absorber plate surface, using corrugated absorber plate, and storing additional thermal energy and releasing it during sunset. In the current study, several studies dealing with past improvements will be reviewed and presented.

\section{Thermal performance.}

\subsection{Energy Analysis}

The thermal efficiency of the solar air heater is defined as the ratio of the useful heat that the solar collector has acquired to the solar radiation falling on the surface of the solar collector [7-9], so the thermal efficiency of the solar air heater can be defined by the following law:

$\eta_{\mathrm{th}}=\frac{\dot{\mathrm{Q}}_{\mathrm{u}}}{\dot{\mathrm{Q}}_{\mathrm{c}}}$

Where $\dot{\mathrm{Q}}_{c}$ represents the solar radiation falling on the surface of the solar collector:

$\dot{\mathrm{Q}}_{\mathrm{c}}=\mathrm{I} \mathrm{A}_{\mathrm{c}}$

While $I$ is the solar radiation falling per unit area of the collector surface and $\mathrm{A}_{\mathrm{C}}$ the surface area of the absorber. $\dot{Q}_{u}$ represents the heat transferred from the solar air heater to the flowing air.

$\dot{\mathrm{Q}}_{\mathrm{u}}=\dot{\mathrm{m}}_{\mathrm{f}} \mathrm{C}_{\mathrm{p}} \cdot \Delta \mathrm{T}_{\mathrm{f}}=\dot{\mathrm{m}}_{\mathrm{f}} \mathrm{C}_{\mathrm{p}}\left(\mathrm{T}_{\mathrm{fo}}-\mathrm{T}_{\mathrm{fi}}\right)$

Thus, the thermal efficiency of the solar air heater can be expressed in the following law [7-9]:

$\eta_{\mathrm{th}}=\frac{\dot{\mathrm{m}}_{\mathrm{f}} \mathrm{C}_{\mathrm{p}}\left(\mathrm{T}_{\mathrm{fo}}-\mathrm{T}_{\mathrm{fi}}\right)}{\mathrm{IA}_{\mathrm{c}}}$

\subsection{Exergy Analysis}

The equations of energy and exergy balance can be expressed in a rate form as [10-13]:

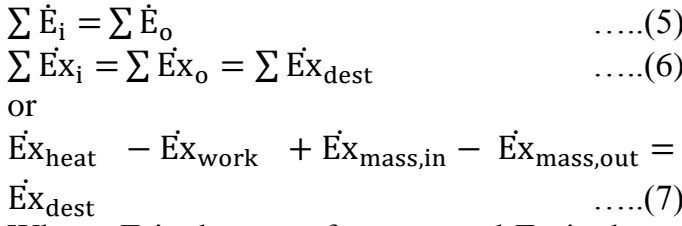

Where, $\mathrm{E}$ is the rate of energy and Ex is the rate of exergy. Equation (7) can be written as:

$\sum\left(1-\frac{\mathrm{T}_{\mathrm{a}}}{\mathrm{T}_{\mathrm{s}}}\right) \dot{\mathrm{Q}}_{\mathrm{c}}-\dot{\mathrm{W}}+\sum \dot{\mathrm{m}}_{\mathrm{i}} \psi_{\mathrm{i}}-\sum \dot{\mathrm{m}}_{\mathrm{o}} \psi_{\mathrm{o}}=$

$\sum \dot{\mathrm{Ex}}_{\mathrm{dest}}$

where, Ta and Ts are temperatures of ambient and absorber plate respectively, and $\psi$ specific exergy, where:
$\psi_{\mathrm{i}}=\left(\mathrm{h}_{\mathrm{i}}-\mathrm{h}_{\mathrm{a}}\right)-\mathrm{T}_{\mathrm{a}}\left(\mathrm{s}_{\mathrm{i}}-\mathrm{s}_{\mathrm{a}}\right)$

.....(9)

$\psi_{\mathrm{o}}=\left(\mathrm{h}_{\mathrm{o}}-\mathrm{h}_{\mathrm{a}}\right)-\mathrm{T}_{\mathrm{a}}\left(\mathrm{s}_{\mathrm{o}}-\mathrm{s}_{\mathrm{a}}\right)$

where, $h$ is the specific enthalpy, and $s$ is the specific entropy. From equations (8) -(10) we get: $\left(1-\frac{\mathrm{T}_{\mathrm{a}}}{\mathrm{T}_{\mathrm{s}}}\right) \dot{\mathrm{Q}}_{\mathrm{c}}-\dot{\mathrm{m}}\left[\left(\mathrm{h}_{\mathrm{o}}-\mathrm{h}_{\mathrm{a}}\right)-\mathrm{T}_{\mathrm{a}}\left(\mathrm{s}_{\mathrm{i}}-\mathrm{s}_{\mathrm{a}}\right)\right]=$ $\sum \dot{E x}_{\text {dest }}$

The enthalpy and entropy changes of air are:

$\Delta \mathrm{h}_{\text {air }}=\mathrm{h}_{\mathrm{o}}-\mathrm{h}_{\mathrm{i}}=\mathrm{C}_{\mathrm{pf}}\left(\mathrm{T}_{\mathrm{fo}}-\mathrm{T}_{\mathrm{fi}}\right)$

$\Delta s_{\text {air }}=s_{o}-s_{i}=C_{p f} \ln \left(\frac{T_{f o}}{T_{f i}}\right)-R \ln \left(\frac{P_{o}}{P_{i}}\right)$

From equations (11)-(13):

$\left(1-\frac{\mathrm{T}_{\mathrm{a}}}{\mathrm{T}_{\mathrm{s}}}\right) \mathrm{I} \mathrm{A}_{\mathrm{c}}-\dot{\mathrm{m}} \mathrm{C}_{\mathrm{pf}}\left(\mathrm{T}_{\mathrm{fo}}-\mathrm{T}_{\mathrm{fi}}\right)+$

$\dot{\mathrm{m}}\left[\mathrm{C}_{\mathrm{pf}} \ln \left(\frac{\mathrm{T}_{\mathrm{fo}}}{\mathrm{T}_{\mathrm{fi}}}\right)-\mathrm{R} \ln \left(\frac{\mathrm{P}_{\mathrm{o}}}{\mathrm{P}_{\mathrm{i}}}\right)\right]=\sum \dot{E x}_{\mathrm{dest}}$

The exergetic efficiency of SAH is represented by ratio of the system net exergy output to input [12, 13].

$\eta_{\mathrm{ex}}=\frac{\dot{\mathrm{Ex}} \mathrm{x}_{\mathrm{o}}}{\dot{\mathrm{Ex}} \mathrm{x}_{\mathrm{i}}}=\frac{\dot{\mathrm{m}}\left[\left(\mathrm{h}_{\mathrm{o}}-\mathrm{h}_{\mathrm{i}}\right)-\mathrm{T}_{\mathrm{a}}\left(\mathrm{s}_{\mathrm{o}}-\mathrm{s}_{\mathrm{i}}\right)\right]}{\left(1-\frac{\mathrm{T}_{\mathrm{a}}}{\mathrm{T}_{\mathrm{s}}}\right) \mathrm{I} \mathrm{A}_{\mathrm{c}}}$

\section{Techniques for improving the thermal performance of SAH}

The improvement of the performance of SAH was the focus of attention of many researchers, who used many methods, and the most important of these methods are:

1. Adding longitudinal fins to the surface of the absorber plate.

2. Attaching baffles to the absorber plate surface.

3. Using corrugated absorber plate.

4. Using the thermal storage material.

The following is a review of the most important theoretical and experimental studies that used the previous improvements:

\subsection{Adding longitudinal fins to the surface of the absorber plate.}

Adding fins to the surface of the absorber plate has a great effect of increasing the heat transfer due to the increase of the heat transfer area, which leads to an increase in the efficiency of the solar air heater. The following is a review of the most important studies that used the longitudinal fins to improve the performance of the solar air heater. In an experimental study by Foued et al. [14], the effect of the air mass flow rate on the temperature and efficiency of the air exiting the collector was verified with the presence or absence of longitudinal fins fixed on the absorber plate, as shown in Figure (4). The results showed that the addition of longitudinal fins at an air mass flow 
rate of $0.016 \mathrm{~kg} / \mathrm{s}$ increased from $34.92 \%$ to $43.94 \%$ respectively.

A theoretical study using the entropy generation method presented by Paisarn [15] to study the effect of fin height and number on the heat transfer from the double path solar heater, as shown in Figure (5). The results showed an important increase in the efficiency of the solar air heater due to the increase in the length and number of the longitudinal fins installed on the absorber plate. This study did not address the effect of air mass flow rate.

In an experimental study conducted by Omojaro and Aldabbagh [16], the thermal performance of a single path solar air heater and a double path solar air heater was investigated, as shown in Figure (6). In both heaters, use steel wire mesh as the absorbing plate. Longitudinal fins are installed on the wire mesh surface. The results showed that the maximum efficiency was $59.62 \%$ and $63.74 \%$ for single and double heaters, respectively.

A theoretical study by evaluating the energy and exergy levels on three types of solar heaters by Alta et al. [17]. The solar air heaters in which this research was studied were as follows: the first type ,(Type I), is without fins and contains double glass cover, the second type, (Type II), contains fins and has a double glass cover and the third type, (Type III), contains fins and has a single glass cover, as shown in Figure (7). The study was done at different air mass flow rates and solar tilt angles. The results of the study showed that Type II was the most efficient, and the air temperature coming out of this solar heater was the highest.

Irfan K. and Emre T. [18] experimentally studied the effect of adding rectangular fins on the performance of a single solar air heater. Two types of fins were used, the first type, (Type I), being the free fins, which are fins fixed on the absorber plate in a way that allows them to move with the airflow, the second type, (Type II), of fins are fins that are tightly attached. The results indicate that Type II solar air had higher efficiency than Type 1.

Another experimental study to perform the effect of adding longitudinal fins to the absorbing plate of a single path solar air heater was conducted by Nilesh R. Pathare [19]. The researchers noted that adding fins led to an improvement in the performance of the solar collector by a rate ranging between 10 to $18 \%$ at different inclination angles of the solar heater.

\subsection{Attaching baffles to the absorber plate surface.}

Although adding both fins and baffles to surfaces aims to increase heat transfer, there is a difference in the mechanism by which this increase occurs. The increase in heat transfer in surfaces containing fins is mainly caused by the increase in the surface area, while the increase in heat transfer in surfaces containing barriers is mainly caused by disturbance in the fluid flow. The following is a review of the most important studies that used the baffles to improve the performance of the solar air heater. Bayrak et al. [20] conducted a theoretical and experimental study on five single-pass solar air heaters at two mass flow rates $0.016 \mathrm{~kg} / \mathrm{s}$ and $0.025 \mathrm{~kg} / \mathrm{s}$. The solar air heaters conducted on the experiments were the following: conventional solar air heater without baffles, solar air heater with Nonstaggered baffles of $6 \mathrm{~mm}$ thickness, solar air heater with staggered baffles of $6 \mathrm{~mm}$ thickness, solar air heater with Non-staggered baffles of thickness of $10 \mathrm{~mm}$. Finally, a solar air heater with $10 \mathrm{~mm}$ staggered baffles, figure (8). The results showed that the highest efficiency was for a solar air heater with staggered baffles of $6 \mathrm{~mm}$ thickness and at a flow rate of $0.025 \mathrm{~kg} / \mathrm{s}$, where the energy efficiency was $77.57 \%$ and the exergy efficiency was $54.54 \%$. The results showed that in this type of solar air heater, staggered baffles produced turbulent flow and reduced dead zones behind baffles.

Ho et al. [21] present an experimental and theoretical study of four double-pass solar air heaters. The first solar heater is a conventional heater without fins and baffles, while the second solar heater has longitudinal fins on both sides of the absorber plate. The third solar heater contains longitudinal fins and baffles on both sides of the absorber plate, figure (9). The research included studying the effect of air recycling on all previous heaters. The results showed that the best performance was for the finned plus baffled double-pass solar air heater, as the efficiency of this heater reached $72.06 \%$ at a mass flow rate $77.04 \mathrm{~kg} / \mathrm{h}$.

Mohammadi and Sabzpooshani [22] conducted a theoretical study on a single-pass solar air heater to study the effect of the number of fins (n), the distance between the baffles ( $\mathrm{L}_{\text {beff }}$ ), the thickness of the baffles $\left(\mathrm{W}_{\text {beff }}\right)$ on the efficiency of the heater and the temperature of the air leaving the heater, and at different mass flow rate values. The study did not show optimal values for the previous variables, but it showed that increasing the number of fins and the thickness of the baffles has an important effect on raising the efficiency of the heater, but increasing the air flow rate more 
than $(0.03 \mathrm{~kg} / \mathrm{s})$ will lead to a decrease in the rate of increase in the heater efficiency.

Ho et al. [23] studied the effect of adding fins and baffles with an air recycling process on a doublepass solar air heater, figure (10). The study noted the possibility of achieving high efficiency when incorporating the previous improvements, which may reach $126.30 \%$ at an air mass flow rate 38.52 $\mathrm{kg} / \mathrm{h}$, air recycling rate $(2)$, and an incident solar radiation $830 \mathrm{~W} / \mathrm{m}^{2}$.

Sunil C. and Narendra T. [24] studied the effect of adding perforated $\mathrm{V}$-shaped baffles on the surface of the absorber plate on the performance of a single-pass solar air heater, figure (11). The results of the study showed the possibility of achieving an improvement in efficiency ranging between (20-80\%) compared to a conventional solar air heater, where the highest improvement in efficiency was at low mass flow rates.

Jalal M. Jalil, et al [25] compared four single-pass solar air heaters. The first is a traditional solar air heater without baffles, the second is a solar heater that contains longitudinal baffles, the third is a solar heater that contains V-shaped baffles, and the fourth is a solar air heater that contains Vshaped baffles in addition to ribs, figure (12). The results showed that the best efficiency was the solar air heater that contains V-shaped baffles in addition to ribs, as its efficiency reached $77.5 \%$ at mass flow rate of $0.0125 \mathrm{~kg} / \mathrm{s}$.

\subsection{Using corrugated absorber plate.}

Changing the shape of the absorber plate from a flat shape to a corrugated shape leads to an increase in the area of heat transfer, thus increasing the efficiency of the solar air heater. The following is a review of the most important studies that used the corrugated absorber plate to improve the performance of the solar air heater.

Karima and Hawlader [26] proposed a theoretical and experimental study to estimate the thermal performance of a solar air heater containing an absorber plate with a v-corrugated surface, and compare its performance with a solar air heater that contains fins, Figure (13). The comparison included the cases of the single pass and double pass heater. The results showed that the $\mathrm{v}$ corrugated solar air heater was more efficient than the one that contained fins, where the percentage increase in efficiency was at different mass flow rates between $10-15 \%$ and $5-11 \%$ in the single and double pass cases respectively.

Another theoretical and experimental study conducted by El-Sebaii et al. [27] to compare between two heaters, the first contains a vcorrugated absorber plate, and the second contains longitudinal fins installed on a flat absorber plate. The results showed that the solar air heater with corrugated absorber plate had a better thermal performance than the finned solar air heater. But when the mass flow rate reaches $0.04 \mathrm{~kg} / \mathrm{s}$, the difference becomes limited. The first heater had higher efficiency than the second one, about $9.3-11.9 \%$. The results also showed that the highest efficiency of the $\mathrm{v}$-corrugated plate heater and the finned heater was at a mass flow rate of $0.0225 \mathrm{~kg} / \mathrm{s}$ and $0.0125 \mathrm{~kg} / \mathrm{s}$ respectively.

Gao et al. [28] conducted a theoretical and experimental study to test the thermal performance of two types of solar air heaters, both of which consist of a wavelike plates. In the first solar air heater type, the wavelike shape of the absorber plate is in the direction of the airflow, while the bottom plate has a wavelike shape perpendicular to the direction of flow, figure (14). In the second type, the bottom plate has a wavelike shape in the direction of the airflow, and the absorber plate has a wavelike shape perpendicular to the direction of flow. The results of the previous two types of solar air heaters will be compared with the results of a conventional flat plate solar air heater. The best performance was for the solar air heater of the second type, as the results showed that the efficiency of the heaters was as follows: $58.9 \%$, $60.3 \%$ and $48.6 \%$ for the first type, the second type and the conventional, respectively.

Som N. S. and Suresh P. S. [29] conducted a theoretical study of a double-pass solar air heater with a v-corrugated absorber plate. The researchers studied the effect of $\mathrm{v}$-corrugated plates angle on solar heater performance. The angles studied are: $0^{\circ}, 30^{\circ}, 45^{\circ}, 60^{\circ}, 90^{\circ}$, and finally $120^{\circ}$. The results of the study showed that the best efficiency was for the $60^{\circ} \mathrm{V}$-corrugated absorber solar air heater. As the table (1) shows:

Table (1): Efficiency for double flow solar air heater for different of $\mathrm{V}$-corrugated plates angle.

\begin{tabular}{|c|c|c|c|c|c|c|}
\hline $\begin{array}{c}\text { Mass } \\
\text { flow } \\
\text { rate } \\
(\mathrm{kg} / \mathrm{s})\end{array}$ & $\begin{array}{c}\text { Flat } \\
\text { plate }\end{array}$ & $30^{\circ}$ & $45^{\circ}$ & $60^{\circ}$ & $90^{\circ}$ & $120^{\circ}$ \\
\hline 0.014 & 53.47 & 65.31 & 65.51 & 65.73 & 63.63 & 61.58 \\
\hline 0.055 & 44.83 & 75.94 & 76.87 & 77.28 & 76.94 & 76.06 \\
\hline 0.083 & 50.8 & 77.74 & 77.95 & 78.53 & 78.43 & 78.38 \\
\hline
\end{tabular}

Another study by Som N. S. and Suresh P. S. [30] compared the performance of double pass solar air heaters with different designs. The first and second heaters contain a v-corrugated absorber and v-corrugated bottom plate, but with two different channel depths. The third heater contained a v-corrugated absorber plate and a flat bottom plate. The fourth and fifth convectors contained an absorber plate in a trapezoidal shape, 
and a bottom plate was also in the shape of a trapezoid, but with different channel depths. The performance of the previous heaters was compared with a conventional double pass heater. The results showed that the best thermal efficiency was for the solar heater that contained a $\mathrm{v}$-corrugated absorber and v-corrugated bottom plate with a depth of $(0.02 \mathrm{~m})$.

\subsection{Using the heat storage materials.}

One of the most important improvements added to solar air heaters is the thermal storage material. These materials are used due to the disruption in solar energy, where energy is stored during sunny days and restored later at night or during times when the sky is cloudy. Energy storage systems are divided into sensible energy storage systems and latent energy storage systems, which use phase-change materials (PCM), which is a solid material that is melted to store energy and heat is subsequently recovered when the material solidified. The most important materials used as phase-changing materials are: calcium chloride hexahydrate, Glaubers salt, paraffins, and fatty acids. The following is a review of the most important studies that used these techniques to improve the performance of the solar air heater.

Alkilani et al. [31] conducted a theoretical study on a single pass solar air heater containing a phase change material (PCM). The researchers studied the temperature of the air exiting the heater during the discharging period at eight values of the air mass flow rate. The heater consists of a single glass cover and a raw of cylinders containing the phase change material (paraffin wax with aluminum powder), figure (15). Air is pumped through the solar heater in crosswise with cylinders. The surface of the cylinders acts as an absorber surface in the heater. The results showed that the air temperature and the discharge time decreased with increasing the mass flow rate. The results also showed the possibility of reaching a temperature $42^{\circ} \mathrm{C}$ at a mass flow rate of $0.05 \mathrm{~kg} / \mathrm{s}$ during evening hours. An experimental study of a double pass solar air heater combined with a thermal storage system was conducted by Krishnananth and Kalidasa [32]. The thermal storage system used in the experiments included aluminum capsules, $4 \mathrm{~cm}$ in diameter and $60 \mathrm{~cm}$ in length, filled with paraffin wax. Researchers studied three different designs for solar air heaters. In the first design, capsules were placed over the absorber plate, while in the second design, aluminum capsules were placed under the absorber plate. In the third design, capsules were placed over the bottom plate. Additional experiments were conducted with a conventional double pass solar air heater (without a thermal storage system). The results of the experiments showed that the combination of a thermal storage system with a solar air heater provides air at a relatively high temperature throughout the day and even during the evening hours. The results also showed that the best thermal efficiency was for the first design, which included placing capsules on the absorber plate.

Bouadila et al. [33] conducted an experimental study on single-pass solar air heater combined with a thermal storage system. The heater contains a set of balls of diameter $0.077 \mathrm{~m}$ coated with black paint and mounted on a steel matrix. The balls are filled with a phase change material. The results showed that the solar energy stored in the solar air heater during the day, produced useful heat during the discharge period at night (11 hours) reaching $200 \mathrm{~W} / \mathrm{m}^{2}$, and the heater provided a daily efficiency of $35 \%$ in the open cycle mode. Daily efficiency is between $32 \%$ and $45 \%$ in Closed / Opened mode.

Fath [34] analyzed the thermal performance of a new design for a single-pass solar air heater where the absorber plate was replaced by a set of tubes filled with a phase-variable material (paraffin wax). The tubes are arranged in straight tubes set or in corrugated set. The results showed that the average daily efficiency of the solar air heater with corrugated tube set reached $63.35 \%$, The air exiting from the heater was kept at a temperature higher than the ambient temperature by $5^{\circ} \mathrm{C}$ for about 16 hours at an airflow rate of $0.02 \mathrm{~kg} / \mathrm{s}$, compared to the efficiency of $38.7 \%$ in the case of the conventional air heater without thermal storage.

One of the studies that used the sensible thermal storage system was the experimental study presented by Dhiman P., Thakur, and N.S. Chauhan S.R. [35]. The experiments were conducted on a double duct air heater containing a filling of layers of wire mesh one on top of the other placed on the upper side of the absorber plate. The researchers studied the two states of airflow: parallel and counter. The results showed that the best thermal efficiency of the packed bed solar air heater was in the case of counter flow.

A.E. Kabeel et al. [36] conducted an experimental study of the thermal performance of a single-pass solar air heater having a v-corrugated plate absorber plate with and without using the phase change material. The phase change material was placed at the bottom of the absorber plate. The results showed that the daily efficiency of the solar heater at the values of flow of air mass $0.062 \mathrm{~kg} / \mathrm{s}, 0.028 \mathrm{~kg} / \mathrm{s}, 0.009 \mathrm{~kg} / \mathrm{s}$, are $62 \%, 52 \%$, $27 \%$ for the solar heater with phase change 
material, while the daily efficiency are $50 \%, 43 \%$, $22.2 \%$ for the solar heater without using phase change material. The air exiting from the heater was kept at a temperature higher than the ambient temperature by $\left(1.5-7^{\circ} \mathrm{C}\right)$ for 3.5 hours, (2$\left.10.5^{\circ} \mathrm{C}\right)$ for 5 hours, $\left(3-13^{\circ} \mathrm{C}\right)$ for 8 hours after sunset at an airflow rates $0.062,0.028$ and 0.009 $\mathrm{kg} / \mathrm{s}$, respectively. Wajahat B. and Hafiz M. Ali [37] conducted an experimental study on a double pass solar air heater that contains a thermal storage system (copper ducts contain paraffin wax and aluminum powder). In this study, the results of three different designs of solar air heaters are compared. The first design was a traditional solar air heater without a heat storage system. The second design contained two copper ducts containing a heat-storing medium, while the third design contained four ducts. Experiments were conducted for two cases when a fan was used during the day or not. The results showed that the third design, when operated without a fan during the day, achieved the highest efficiency (97\%). The maximum storage time was (2.5) hours, while the storage time was (1.5) hours in case the fan was running for the same design. A new design for a solar air heater combined with a thermal storage system was proposed by Qusay A. Jawad et al. [38]. The design included two parts. The first, horizontal, single-pass section contains aluminum chip coated with black thermal dyes. The second part is vertical and contains five copper tubes filled with paraffin wax mixed with nano-silicon carbide (nano-SiC). The results indicated that the new design of the solar heater can raise the outdoor air temperature to $64.4^{\circ} \mathrm{C}$ for the period from $1 \mathrm{p}$. m. to $3 \mathrm{p} . \mathrm{m}$., and the temperature of the air leaving the heater is higher than the ambient temperature for a period of not less than 3 hours after sunset.

\section{Conclusion}

In this paper, a review of various techniques to improve the thermal performance of solar air heaters used in previous theoretical and experimental studies is performed. The following conclusions are drawn:

1- Adding fins to the surface of the absorber plate in a single-pass or double-pass solar air heater has a great effect on increasing heat transfer and thus improving thermal efficiency. For example, in the study of Foued et al. [14], the efficiency increased from $34.92 \%$ to $43.94 \%$ as a result of adding longitudinal fins. While another study showed that it is possible to reach an efficiency of $64 \%$ using fins [16].
2- Baffles gives turbulence to the air flow through solar air heater, thus increasing heat transfer coefficient, and thermal efficiency. Results indicated that in the staggered baffles solar air heater, the efficiency can reach approx. $77 \%$ [20].

3- The use of a corrugated absorber plate leads to a significant increase in the efficiency of the solar air heater. Results indicated that in the $60^{\circ}$ v-corrugated absorber solar air heater the efficiency can reach approx. 78.53\% [29].

4- The heat stored in the solar air heater by latent or sensible storage material can be used in the producing of useful heat after the absence of solar radiation and raise daily efficiency, for example the energy stored can produce 200 $\mathrm{W} / \mathrm{m}^{2}$ during discharge period at night for a period of up to 11 hours [33].

\section{Nomenclature}

$\mathrm{A}_{\mathrm{c}}$ the surface area of the absorber, $\mathrm{m}^{2}$.

$\mathrm{C}_{\mathrm{p}}$ specific heat of air at constant pressure $(\mathrm{kJ} / \mathrm{kg} \mathrm{K})$.

$\dot{\mathrm{E}} \quad$ rate of energy, $\mathrm{kW}$.

Ex rate of exergy, $\mathrm{kW}$.

$\mathrm{h}$ specific enthalpy, $(\mathrm{kJ} / \mathrm{kg})$.

I solar radiation falling per unit area of the collector surface, $\mathrm{W} / \mathrm{m}^{2}$.

$\dot{\mathrm{Q}}_{\mathrm{u}} \quad$ heat transferred from the solar air heater to the flowing air, $\mathrm{kW}$.

$\dot{Q}_{c} \quad$ solar radiation falling on the surface of the solar collector, $\mathrm{kW}$.

S specific entropy, $(\mathrm{kJ} / \mathrm{kg} \mathrm{K})$.

SAH Solar Air Heater

$\mathrm{T}_{\mathrm{f}} \quad$ Temperature of air, $\mathrm{K}$.

\section{Greek Symbols}

$\begin{array}{cl}\eta_{\text {ex }} & \text { exergetic efficiency } \\ \eta_{\text {th }} & \text { Thermal efficiency. } \\ \psi & \text { specific exergy }\end{array}$

\section{Subscripts}

$\begin{array}{cl}\text { a } & \text { Ambient. } \\ \text { dest } & \text { destroyed } \\ \mathrm{f} & \text { Working fluid (air). } \\ \mathrm{i}, \mathrm{o} & \text { Inlet and outlet air flow. } \\ \mathrm{s} & \text { Absorber plate. }\end{array}$




\section{REFERENCE}

[1] D. J. Close, "Solar air heaters for low and moderate temperature applications", Solar Energy, Vol. 7 , No. 3, pp. 117-24, 1963.

[2] S. A. Kalogirou, "Solar thermal collectors and applications", Progress in Energy and Combustion Science, Vol. 30,pp. 231-295, 2004.

[3] M. M. Alkilani, K. Sopian, Sohif Mat, and M. A. Alghoul, "Output air temperature prediction in a solar air heater integrated with phase change material", European Journal of Scientific Research, Vol.27, No.3, pp.334-341, 2009.

[4] V.V. Tyagi , N.L. Panwar, N.A. Rahima, Richa Kothari, "Review on solar air heating system with and without thermal energy storage system", Renewable and Sustainable Energy Reviews, Vol. 16, Issue 4, pp. 2289-2303, 2012.

[5] Mahmud M. Alkilani , K. Sopian, M.A. Alghoul, M. Sohif, and M.H. Ruslan, "Review of solar air collectors with thermal storage units", Renewable and Sustainable Energy Reviews, Vol. 15, Issue 3, pp. 1476-1490, 2011.

[6] S. Chamoli, R. Chauhana, N.S. Thakur, and J.S. Saini, "A review of the performance of double pass solar air heater", Renewable and Sustainable Energy Reviews, Vol. 16, Issue 1, pp. 481-492, 2012.

[7] S. P. Sukhatme, J. K. Nayak, "Solar Energy: Principles of Thermal Collection and Storage", Tata McGraw Hill, New Delhi, ISBN (10):007014296-3, Third Edition, 2009.

[8] H. P. Garg, J. Prakash, "Solar Energy: Fundamentals and Applications", Tata McGraw Hill, New Delhi, ISBN 0074631411, 9780074631416, , 1997.

[9] John A. Duffie, William A. Beckman, "Solar engineering of thermal processes", USA, John Wiley \& Sons, ISBN 978-0-470-87366-3, Fourth Edition, 2013.

[10] H. F. Oztop , F. Bayrak , A. Hepbasli, "Energetic and exergetic aspects of solar air heating (solar collector) systems", Renewable and Sustainable Energy Reviews, Vol. 21, pp. 59-83, 2013.

[11] Yunus A. Cengel, Michael A. Boles, "Thermodynamics: An Engineering Approach", Mcgraw-hill Series in Mechanical Engineering, ISBN-10: 0072884959, 5th Edition, 2006.

[12] Hüseyin Benli, "Experimentally derived efficiency and exergy analysis of a new solar air heater having different surface shapes", Renewable Energy, Vol. 50, pp. 58-67, 2013.

[13] S.R. Park , A.K. Pandey , V.V. Tyagi , and S.K. Tyagi, "Energy and exergy analysis of typical renewable energy systems", Renewable and Sustainable Energy Reviews, Vol. 30, pp. 105123,2014
[14] F. Chabane , N. Moummi , S. Benramache, "Experimental study of heat transfer and thermal performance with longitudinal fins of solar air heater", Journal of Advanced Research, Vol. 5, Issue 2, pp. 183-192, 2014.

[15] P. Naphon, "On the performance and entropy generation of the double-pass solar air heater with longitudinal fins", Renewable Energy, Vol. 30, pp. 1345-1357, 2005.

[16] A.P. Omojaro, L.B.Y. Aldabbagh, "Experimental performance of single and double pass solar air heater with fins and steel wire mesh as absorber", Applied Energy, Vol. 87, Issue 12, pp. 3759-3765, 2010.

[17] Deniz Alta , ,Emin Bilgili , C. Ertekin , Osman Yaldiz, "Experimental investigation of three different solar air heaters: energy and exergy analyses", Applied Energy, Vol. 87, pp. 29532973, 2010.

[18] I. Kurtbas and E. Turgut, "Experimental Investigation of Solar Air Heater with Free and Fixed Fins: Efficiency and Exergy Loss", International Journal of Science \& Technology, Vol. 1, No 1, pp.75-82, 2006.

[19] N. R.Pathare, "Performance Analysis on Continuous Longitudinal Fins Solar Air Heater", International Journal of Innovations in Engineering and Science, Vol.2, No.8, pp.5-8 ,2017.

[20] F. Bayraka, H. F. Oztopb, A. Hepbasli, " Energy and exergy analyses of porous baffles inserted solar air heaters for building applications ", Energy and Buildings, Vol. 57, pp. 338-345, 2013.

[21] Chii-Dong Ho, H. Chang, Rei-Chi Wang, ChunSheng Lin, "Performance improvement of a double-pass solar air heater with fins and baffles under recycling operation", Applied Energy, Vol. 100, pp. 155-163, 2012.

[22] K. Mohammadi, M. Sabzpooshani, "Comprehensive performance evaluation and

parametric studies of single pass solar air heater with fins and baffles attached over the absorber plate", Energy, Vol. 57, pp. 741-750, , 2013.

[23] C.D. Ho, H.M. Yeh, T.W. Cheng, T.C. Chen, and R.C. Wang, " The influences of recycle on performance of baffled double-pass flat-plate solar air heaters with internal fins attached ", Applied Energy, Vol. 86, Issue 9, pp. 1470-1478, 2009.

[24] S. Chamoli, and N. Thakur, "Performance study of solar air heater duct having absorber plate with $\mathrm{V}$ down perforated baffles", Songklanakarin Journal of Science and Technology, Vol.36, No.2, pp. 201-208, 2014.

[25] J. M. Jalil, G. K. Salih, Y. A. Madhi, "Performance Study of Solar Air Heater with Thermally Conducted Multi V Shaped Baffles 
and Ribs", Engineering and Technology Journal, Vol. 36, Part A, No. 8, pp. 930-938, 2018.

[26] M. A. Karima, M.N.A Hawladerb, " Performance investigation of flat plate, vcorrugated and finned air collectors ", Energy, Vol. 31, pp. 452-470, 2006.

[27] A. El-Sebaii, S. Aboul-Enein, M.R.I. Ramadan , S.M. Shalaby, B.M. Moharram, "Thermal performance investigation of double pass-finned plate solar air heater", Applied Energy, Vol. 88, Issue 5, pp. 1727-1739, , 2011.

[28] W. Gao , W. Lin , Tao Liu a , C. Xia , "Analytical and experimental studies on the thermal performance of cross-corrugated and flatplate solar air heaters", Applied Energy, Vol. 84, pp. 425-441, 2007.

[29] S.N. Saha, and S.P. Sharma, "Analysis of Thermohydraulic Performance of Double Flow V-Corrugated Absorber Solar Air Heater", International Energy Journal, Vol.16, pp. 131142, 2016.

[30] S.N. Saha, and S.P. Sharma, "Performance Evaluation of Corrugated Absorber Double Flow Solar Air Heater Based on Energy, Effective and Exergy Efficiencies", International Journal of Mechanical \& Mechatronics Engineering, Vol. 17, No.1, pp. 63-76, , 2017.

[31] M. M. Alkilani, K. Sopian, S. Mat, M. A. Alghoul, "Output air temperature prediction in a solar air heater integrated with phase change material", European Journal of Scientific Research, Vol.27, No.3, pp.334-341, 2009.

[32] S.S. Krishnananth, K. K. Murugavel, "Experimental study on double pass solar air heater with thermal energy storage", Journal of King Saud University-Engineering Sciences, Vol.25, Issue 2, pp. 135-140, 2013.

[33] B. Salwa, K. Sami, L. Mariem, S. Safa, F. Abdelhamid. "Performance of a new solar air heater with packed-bed latent storage energy for nocturnal use", Applied Energy, Vol.110, pp.26775, 2013.

[34] H. E. S. Fath, "Thermal performance of simple design solar air heater with builtin thermal energy storage system", Energy Conversion and Management, Vol. 36, pp.989-97, 1995.

[35] P. Dhiman, N.S. Thakur, S.R. Chauhan, "Thermal and thermohydraulic performance of counter and parallel flow packed bed solar air heaters", Renewable Energy, Vol. 46 ,pp.259268, 2012.

[36] A.E. Kabeel , M.E.Zayed , A-Khalil , S.M. Shalaby, "Improvement of thermal performance of the solar air heater by using V-corrugated absorber plate and PCM for hybrid desalination application", Twentieth International Water Technology Conference, IWTC20, Hurghada, 1820 May 2017.

[37] Wajahat Baig, Hafiz M. Ali, "An experimental investigation of performance of a double pass solar air heater with foam aluminum thermal storage medium", Case Studies in Thermal Engineering, Vol. 14, pp. 100440, 2019.

[38] Qusay A. Jawad, Aedah M.J. Mahdy, Ahmed H. Khuder , Miqdam T. Chaichan,, "Improve the performance of a solar air heater by adding aluminum chip, paraffin wax, and nano-SiC", Case Studies in Thermal Engineering, Vol. 19, pp. 100622, 2020. 


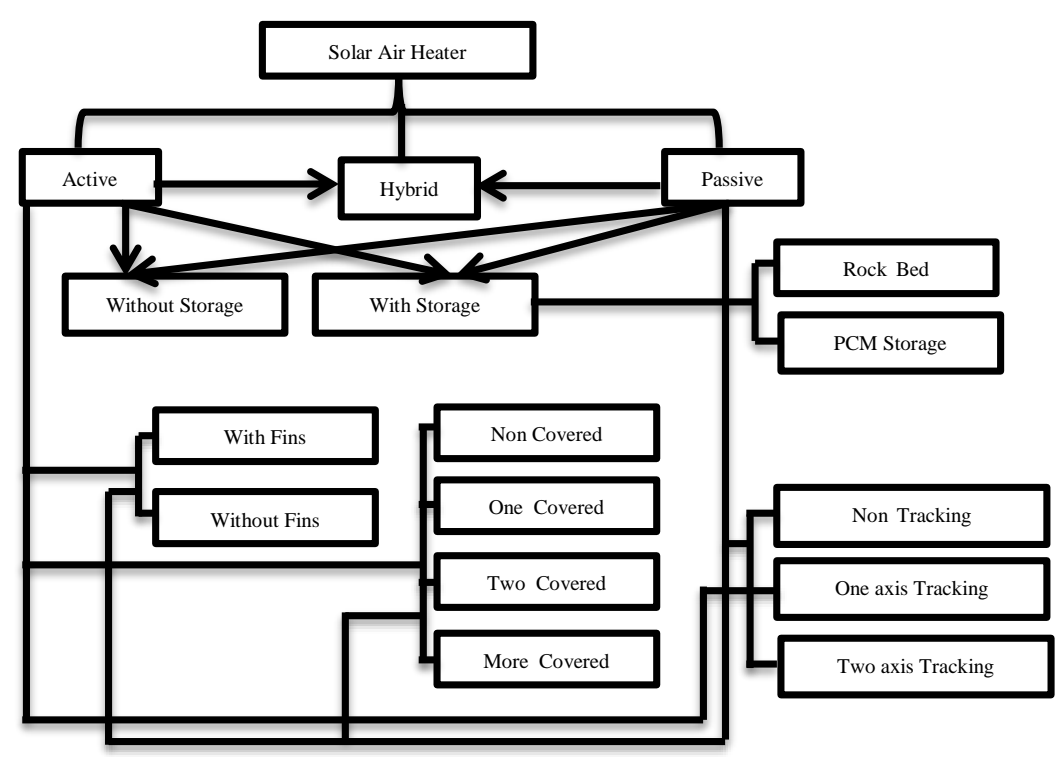

Figure (1): Classification of the solar air heaters based on Tyagia et al. [4].
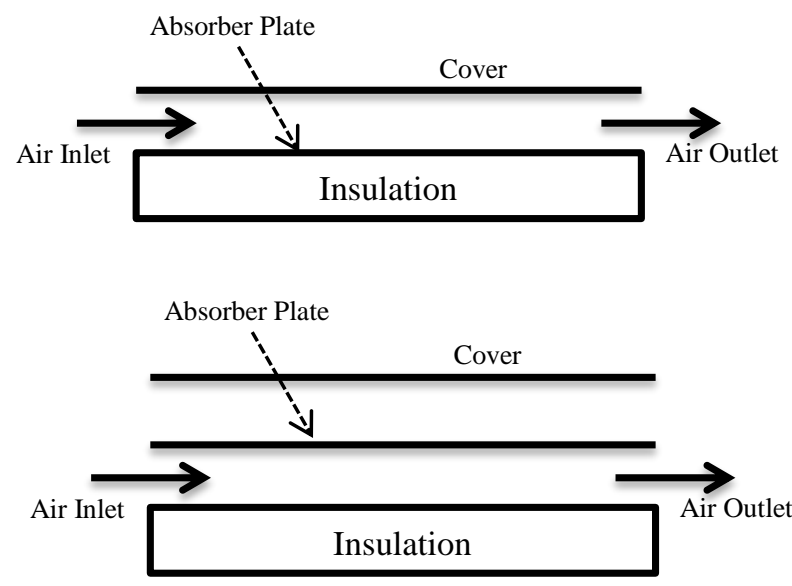

Figure (2): Two types of single-pass solar air heater. 


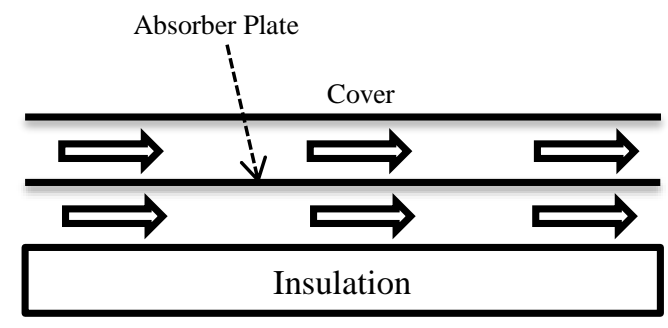

(a)

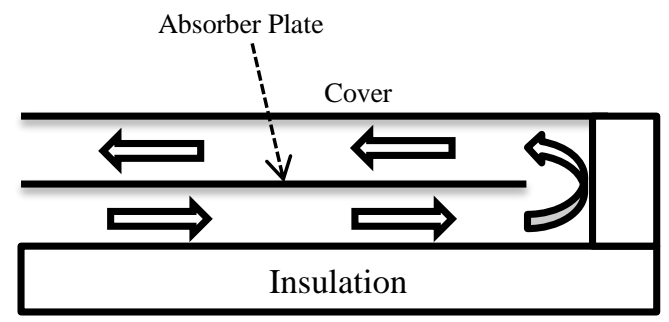

(b)

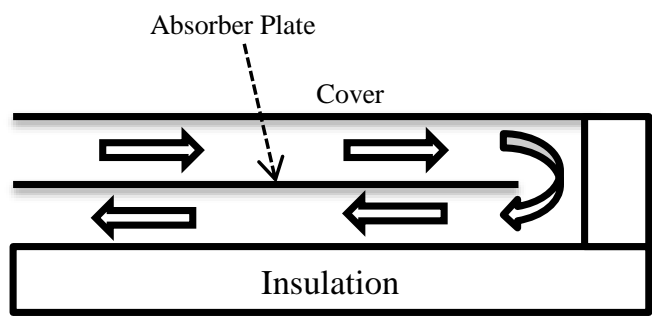

(c)

Figure (3): Double pass solar air heater (a-Parallel flow, b \& c - counter flow).

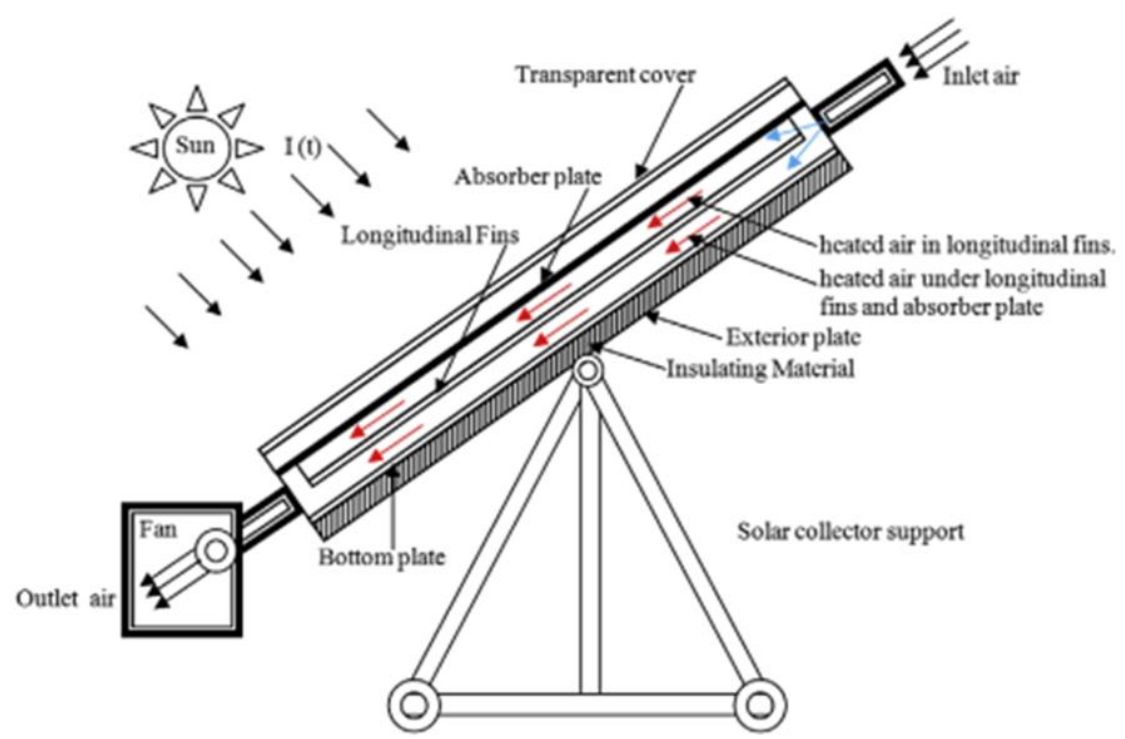

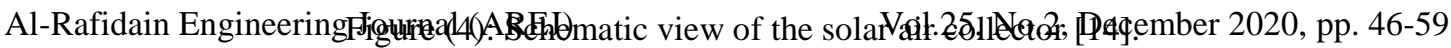




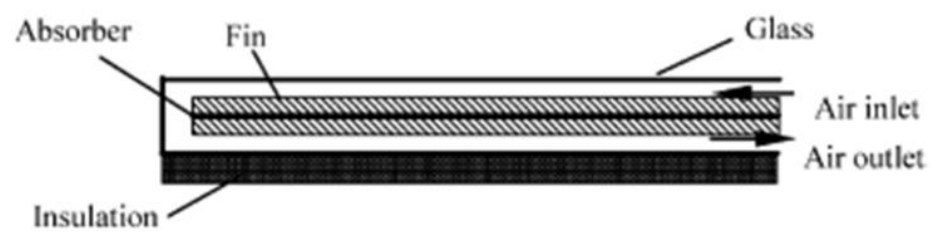

\section{1}

Figure (5): Schematic diagram of the solar air heater [15].

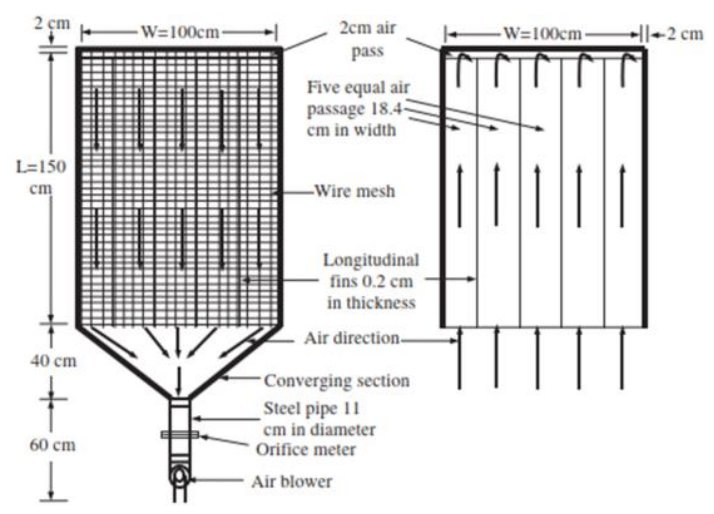

Figure (6): double pass solar air heater showing: (a) lower pass channel, and (b) upper pass channel [16].

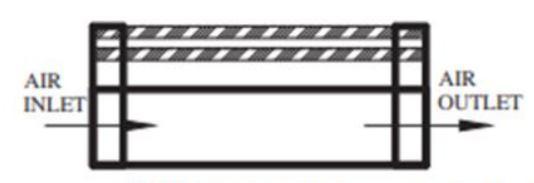

(a) TYPE I (with double glass cover and without fins

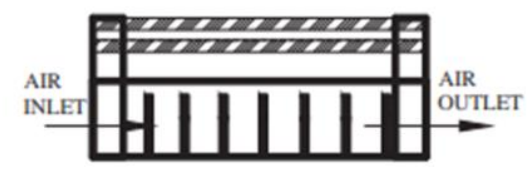

(b) TYPE II (with double glass cover and fins)

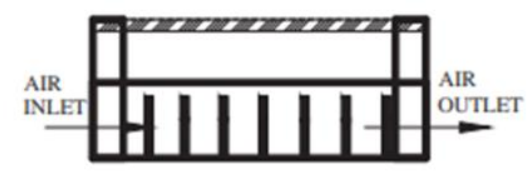

(c) TYPE III (with single glass cover and fins)

Al-Rafidain Engineering Journal (AREJ)
Figure (7): Construction details of Type I, Type II and Type III [17]. 
(a)
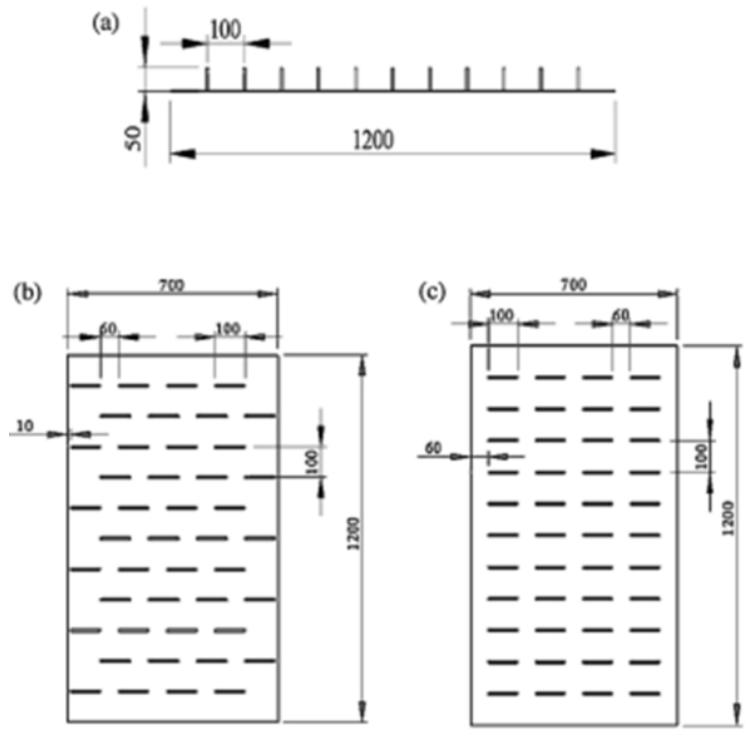

Figure (8): Various views of the SAH (a) side view of the Non-staggered and staggered arrays, (b) top view of the staggered array, and (c) top view of the Non-staggered array [20].

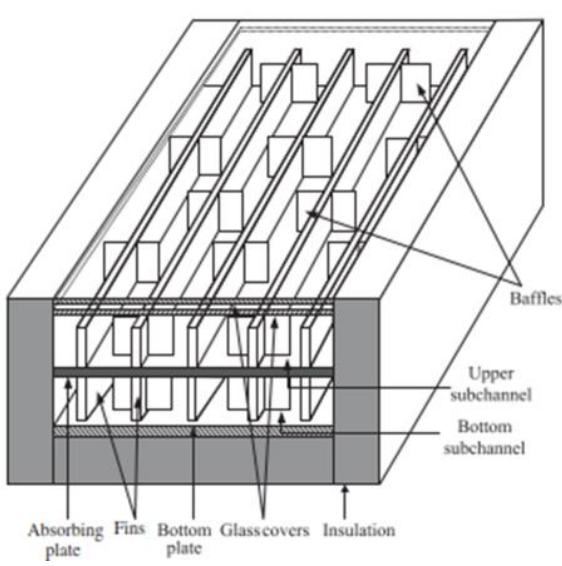

Figure (9): A schematic drawing of a fined plus baffled double-pass solar air heater [4].

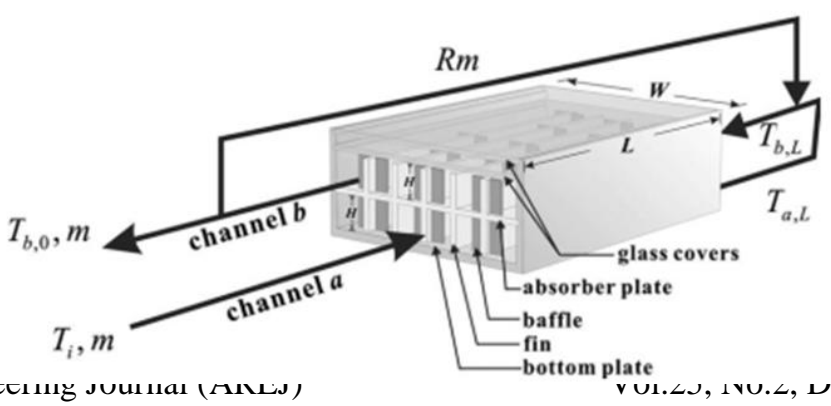
ember 2020, pp. 46-59

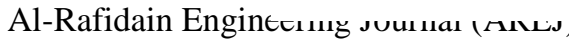

Figure (10): The baffled SAH with internal fins attached and external recycle [23]. 


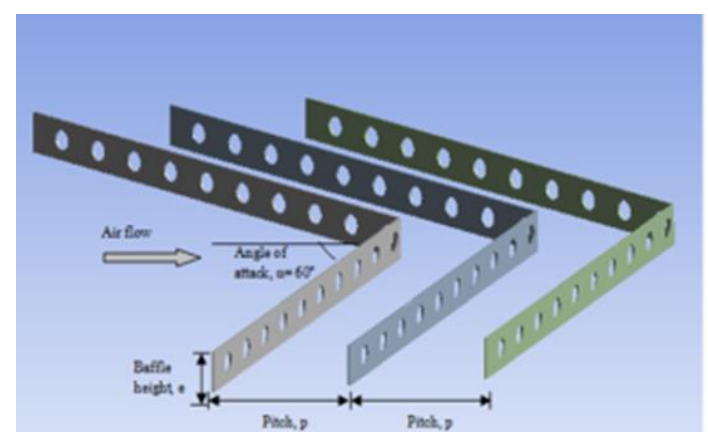

Figure (11): Schematic diagram of the V down perforated baffles [24].

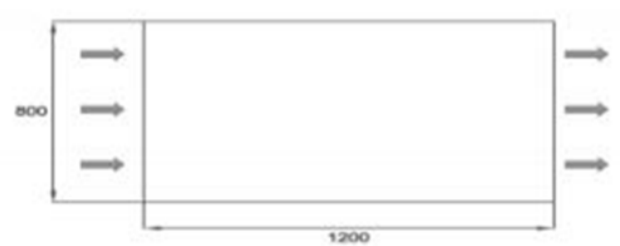

(a)

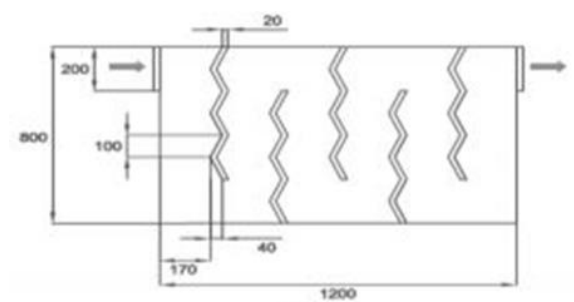

(c)

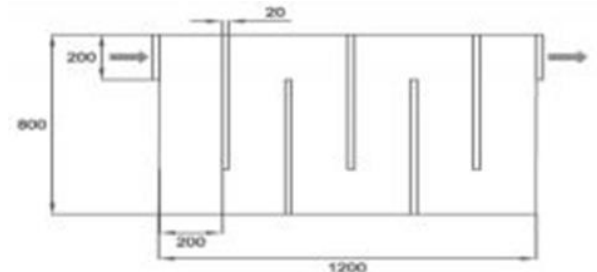

(b)

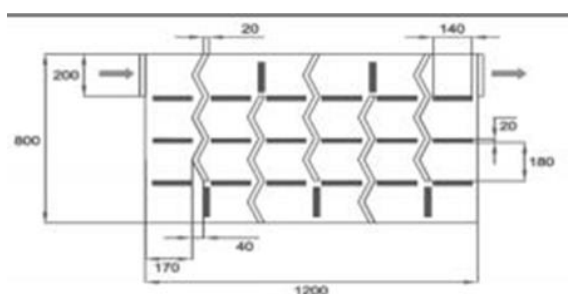

(d)

Figure (12): Upper view of collectors for a) smooth absorber plate b) straight baffles c) $\mathrm{V}$ shaped baffles d) V shaped baffles and ribs [25].

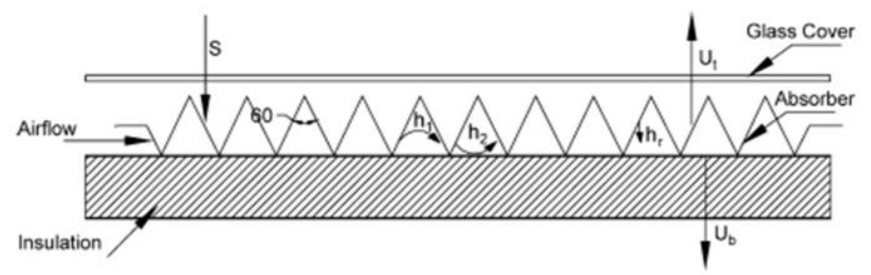

(a)

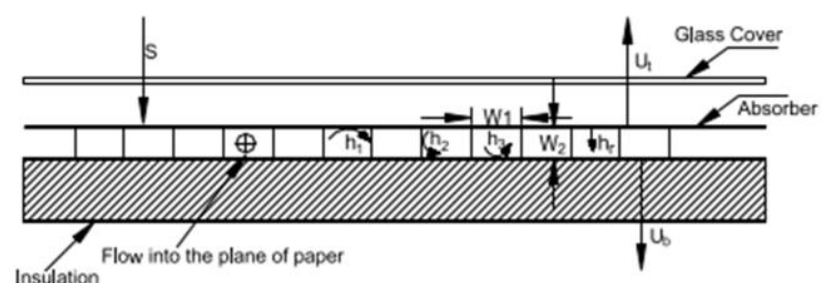

Al-Rafidain Engineering Journal (AREJ)

(b)

Vol.25, No.2, December 2020, pp. 46-59

Figure (13): (a) V-groove air collector, (b) Finned collector [26]. 


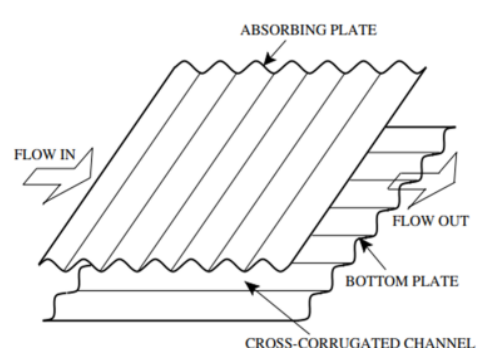

Figure (14): Schematic description of the type 1 solar air heater which has a cross-corrugated absorbing plate and bottom plate [28].

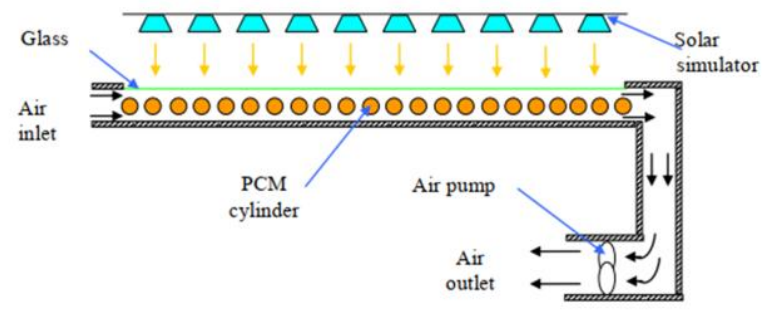

Figure (15): single pass solar air heater containing PCM [31].

\title{
مراجعة عن سخانات الهواء الشمسية: تقنيات تحسين الأداء الحراري
}

\author{
عمر محمد حمدون
}

eng.omar.m.hamdoon@uomosul.edu.iq

جامعة الموصل ـ كلية الهندسة - قسم انهندة الميكانيكية

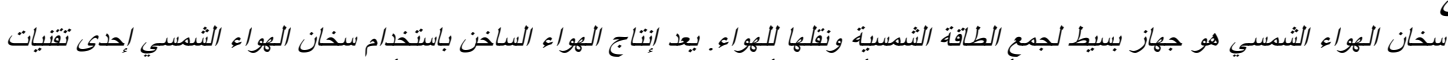

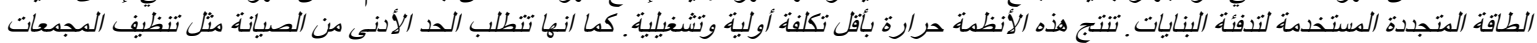

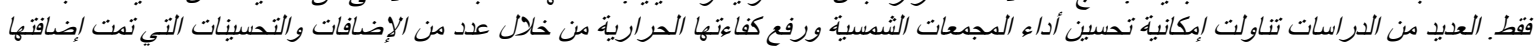

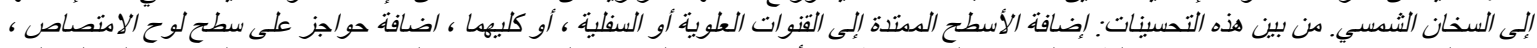

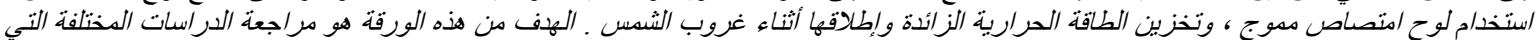

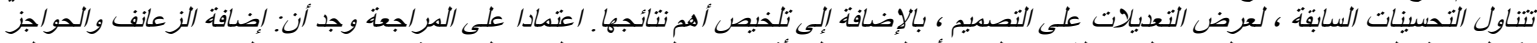

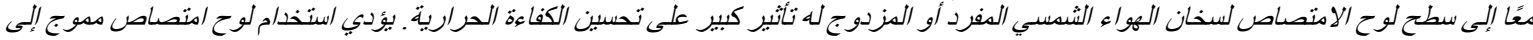

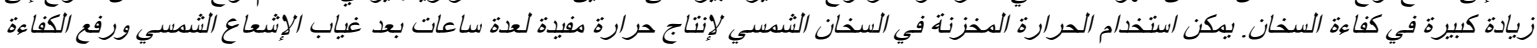
البيومبة له.

الكثمات الد/الهه :

مسخن الهواء الثدسي، تحسين الاداء، الزعانف، الحواجز، لوح الامتصاص المتصوج، المواد متغبرة الطور. 